\title{
al-Balagh
}

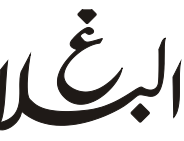

http://ejournal.iain-surakarta.ac.id/index.php/al-balagh

\section{Voluntary Counseling and Testing untuk Orang Berisiko HIV/AIDS}

\section{Diah Astuti Saputri Retnaningsih}

Mahasiswa akhir Bimbingan dan Konseling Islam, IAIN Surakarta

Keywords:

Counseling, Testing, and HIV/ AIDS.

\begin{abstract}
Abstrak
Studi dilakukan untuk mengetahui lebih jauh pelaksanaan layanan Voluntary Counseling And Testing (VCT) bagi orang berisiko HIV/ AIDS. Ini merupakan program layanan pemerintah, mulai dari proses konseling sampe pada tes dan pasca tes, guna menurunkan risiko tertular HIVIAIDS. Dengan pendekatan deskriptif-kualitatif, studi ini menunjukkan bahwa pelaksanaan VCT ini sangat penting, karena prosesnya menekankan pada pentingnya penerimaan klien, menjalin hubungan, eksplorasi, identifikasi, memberi informasi, perencanaan kegiatan, menentukan keputusan, testing, sampai pada membangun kesiapan klien, membuat perencanaan, membacakan hasil tes, memberikan penjelasan sesuai hasil tes, memberikan dukungan, semangat, dan motivasi. Selain bisa meminimalisir resiko tertular, juga menjadikan orang yang sudah tertular bisa lebih optimistis dalam menjalani kehidupan.
\end{abstract}

\begin{abstract}
The Study aims to know further about the implementation of Voluntary Counseling and Testing (VCT) to people with the possibility of being infected by HIV/AIDS. It is governmental service program starting from counseling, testing, and post testing in order to minimize the contagious risk of HIV/AIDS. Through the qualitative-descriptive approach, this study showed that the implementation of VCT program is very important because the process emphasizes the acceptance of client, building relationship, exploring, identifying, giving information, planning activity, determining decision, testing, up to developing the readiness of client, making planning, reading off the test's result, explaining result of the test, giving support and motivation. All of these are purposed to minimize the contagious risk, and make the infected one more optimistic in experiencing life.
\end{abstract}




\section{A. Pendahuluan}

Sejak kasus pertama dilaporkan pada tahun 1981, HIV/AIDS sudah menjadi perhatian penting, tidak hanya di kalangan dunia kedokteran, tetapi juga di kalangan pengambil kebijakan, pemimpin agama, dan masyarakat dunia pada umumnya. Sementara di Indonesia, HIV/AIDS mulai dikenal pada awal Januari 1986. Sejak saat itu, perkembangan kasus HIV/AIDS berkembang makin pesat karena vaksin penangkalnya belum ditemukan. Kasus HIV/AIDS ini disebabkan oleh perilaku yang kurang baik, seperti homoseksual, heteroseksual, penguna Napza, tato dan tindik, transfusi darah.

Untuk membantu perubahan perilaku sehingga risiko tertular HIV menurun, pemerintah pun membuka sebuah layanan yang disebut Voluntary Counseling and Testing (VCT). Layanan yang merupakan gabungan dari proses konseling dan tes HIV. Salah satu keistimewaan dari layanan VCT ini tidak hanya pada proses konseling, tapi sampai pada proses tes dan pos tes. Selain bertujuan untuk membantu perubahan perilaku, juga guna mencegah penularan HIV, meningkatkan kualitas hidup ODHA, serta untuk sosialisasi dan mempromosikan layanan dini. Seperti pada penelitian Nila Titis Asrining Tyas (2010), VCT dianggap sangat bermanfaat bagi PSK dan mampu mengubah paradigma hidup para PSK terkait pentingnya kesehatan serta mampu meningkatkan kewaspadaan dan proteksi diri terhadap faktor-faktor risiko yang ada. Maka peneliti membatasi penelitian pada pelaksanaan layanan voluntary counseling and testing dalam menangani orang berisiko HIV/AIDS. Penelitian ini berbeda dengan penelitian yang terdahulu karena dalam penelitian ini voluntary counseling and testing tidak hanya untuk orang berisiko HIV/AIDS, namun juga untuk pasien TB. Di Klaten sendiri, ada beberapa tempat yang memiliki layanan voluntary counseling and testing yaitu RSUP dr. Soeradji Tirtonegoro, Balai Kesehatan Paru Masyarakat (BKPM) Klaten, RSJD Dr. Soedjarwadi, RSI Klaten, dan beberapa puskesmas. Namun BKPM Klaten memiliki keistimewaan dibandingkan dengan tempat lainnya yaitu dari klien yang ditangani dalam 
layanan voluntary counseling and testing. Klien layanan VCT di BKPM tidak hanya orang berisiko HIV/AIDS seperti tempat lain, namun juga untuk pasien TB.

\section{Konselor Voluntary Counseling and Testing}

Konselor adalah seorang ahli yang memberi bantuan kepada klien sesuai permasalahan klien. Konselor merupakan unsur utama dalam pelaksanaan suatu layanan konseling, termasuk juga dalam layanan voluntary counseling and testing. Untuk menjadi konselor voluntary counseling and testing tidak memiliki banyak syarat. Syarat utama menjadi konselor voluntary counseling and testing adalah mengikuti pelatihan khusus tentang HIV/ AIDS yang berstandar nasional sesuai WHO yang hanya dilaksanakan beberapa hari dan memiliki sertifikat pelatihan tersebut. Selain itu untuk menjadi konselor yang berkompeten harus memiliki kepribadian yang baik, meliputi pribadi yang intelegen, memiliki minat kerjasama, sifat toleransi; pendidikan yang sesuai dengan bidang konseling yaitu strata satu (S1), S2, S3 dan sekurang-kurangnya pernah mengikuti pelatihan tentang bimbingan dan konseling; pengalaman suka membantu mendiagnosis dan mencari alternatif solusi terhadap klien; dan kemampuan, meliputi berbagai keterampilan konseling dan komunikasi. Keterampilan tersebut antara lain adalah keterampilan attending (keterampilan untuk menghadirkan klien dalam proses konseling), keterampilan mengundang pembicaraan terbuka untuk memberi kesempatan klien agar mengeksplorasi dirinya sendiri dengan dukungan pewawancara, keterampilan parafrase untuk memperbaiki hubungan antar pribadi, keterampilan refleksi perasaan untuk merespon keadaan perasaan klien terhadap situasi yang sedang dihadapi, keterampilan konfrontasi meliputi keterampilan interpersonal, keterampilan diagnostic, keterampilan memotivasi dan keterampilan manajemen. Menurut Suherman, konselor profesional harus memiliki etik yaitu melakukan konseling sesuai dengan kemampuannya, memahami hakhak konseling, menjaga kerahasiaan, objektivitas, mengindari terjadinya 
hubungan secara intim dengan klien dan senantiasa meningkatkan kemampuan dan ketrampilan dalam konseling.

\section{Klien Voluntary Counseling and Testing}

Klien adalah seseorang yang membutuhkan bantuan atau seseorang yang diberikan bantuan oleh konselor. Suatu layanan konseling tidak dapat berjalan jika tidak ada klien. Klien voluntary counseling and testing di BKPM Klaten terdiri dari dua jenis yaitu pasien TB dan orang berisiko HIV/ AIDS. Yang termasuk dalam orang berisiko HIV/AIDS antara lain adalah LSL (laki suka laki), gay, homoseksual, heteroseksual, pemakai narkoba, pemakai jarum suntik bergantian. Klien voluntary counseling and testing termasuk klien sukarela, karena klien datang pada konselor atas kesadaran diri sendiri untuk memperoleh informasi atau mencari pemecahan masalah yang dihadapi. Menurut Farid (2013), klien sukarela ini biasanya memiliki ciri mudah terbuka, hadir atas kehendak sendiri, dapat menyesuaikan diri dengan konselor, sungguh-sungguh dalam mengikuti proses konseling, berusaha mengemukakan sesuatu dengan jelas, bersedia mengungkapkan rahasia, bersikap sahabat, dan mengikuti proses konseling.

\section{Metode dalam Voluntary Counseling and Testing}

Metode merupakan suatu jalur atau jalan yang harus dilalui untuk pencapaian suatu tujuan. Dalam hal mencapai tujuan voluntary counseling and testing yaitu mencegah penularan HIV dan meningkatkan kualitas hidup ODHA, maka diperlukan adanya suatu metode. Metode yang digunakan dalam layanan voluntary counseling and testing adalah metode konseling individual. Metode konseling individual adalah upaya pemberian bantuan diberikan secara individual dan langsung bertatap muka (berkomunikasi) antara konselor dengan konseli. Dengan perkataan lain pemberian bantuan diberikan melalui hubungan bersifat face to face relationship (hubungan empat mata), yang dilaksanakan dengan wawancara antara konselor dengan konseli. (Willis 2004, 66) 
Dalam pelaksanaan konseling dengan menggunakan metode konseling individual ini memiliki kelebihan yaitu konselor lebih mudah terpusat kepada klien dan klien lebih mudah percaya kepada konselor. Sedangkan untuk kekurangan adalah klien bisa merasa diinterogasi dengan hanya adanya konselor dan klien.

\section{Teknik Pendekatan dalam Voluntary Counseling and Testing}

Suatu layanan pasti memiliki teknik yang digunakan untuk lebih mudah dan cepat mencapai tujuan. Dalam voluntary counseling and testing agar tujuan dapat tercapai dengan mudah dan cepat, teknik pendekatan yang digunakan adalah eklektik. Teknik pendekatan eklektik merupakan gabungan teknik pendekatan antara direktif dan nondirektif. Teknik ini dikembangkan oleh Frederick Thorne dengan tujuan untuk menggantikan tingkah laku yang terlalu komplusif dan emosional dengan tingkah laku yang bercorak lebih rasional dan konstruktif. Kelebihan dari teknik yang dikembangkan oleh Frederick Thorne yaitu karena menerapkan dan memadukan berbagai pendekatan, menggunakan variasi dalam prosedur dan teknik sehingga dapat melayani klien sesuai dengan kebutuhannya dan sesuai dengan ciri khas masalah yang dihadapi klien. Serta kekurangan dari teknik pendekatan ini adalah klien merasa binggung jika konselor merubah strategi konseling sewaktu-waktu sesuai dengan kebutuhan saat konseling, maka konselor dituntut untuk menguasai semua pendekatan sehingga mengerti kapan harus menerapkan pendekatan-pendekatan tersebut. (Wibowo 2003, 67)

\section{Prinsip-prinsip Voluntary Counseling and Testing}

Prinsip-prinsip dalam konseling harus berkenaan dengan sasaran pelayanan, masalah individu, tujuan dan proses penanganan masalah, program pelayanan, dan pelaksanaan pelayanan. Sedangan prinsip dasar dalam voluntary counseling and testing ada 4, yaitu rahasia, sukarela, konseling dan persetujuan. 
Rahasia. Hasil pemeriksaan hanya boleh diketahui oleh yang bersangkutan dan konselor yang menanganinya. Boleh dibukakan statusnya kepada orang lain, dengan melalui persetujuan dari yang bersangkutan atau yang bersangkutan menyampaikan sendiri.

Sukarela. Untuk tes HIV sifatnya sukarela (voluntary), tidak ada paksaan dari konselor. Konselor hanya mengajaknya secara persuasive, terutama bagi klien yang memiliki risiko tinggi untuk terpapar HIV.

Konseling. Mempelajari pengalaman-pengalaman hidup klien, dalam mengatasi permasalahan yang dapat menimbulkan stres atau depresi pada dirinya. Mempelajari latar belakang perilaku berisiko klien termasuk diantaranya kemungkinan-kemungkinan melukai diri sendiri atau melukai orang lain, seandainya hasilnya positif. Menilai pemahaman klien mengenai HIV/AIDS, konseling, keuntungan-keuntungannya melakukan VCT, dll.

Persetujuan. Klien harus mengisi formulir persetujuan untuk melakukan tes (inform concent), yang kemudian akan ditandatangani oleh klien dan konselor.

Namun selain prinsip dasar tersebut prinsip-prinsip yang lainnya adalah empati, mendengarkan, memberikan informasi yang tepat, dan alih tangan. Sedang menurut Prayitno dan Erma Amti (2003, ) menyatakan bahwa prinsip-prinsip konseling adalah berkenaan dengan sasaran pelayanan, masalah individu, program layanan, pelaksanaan layanan, tujuan dan proses penanganan masalah.

\section{Indikator Keberhasilan Voluntary Counseling and Testing}

Suatu layanan ada pasti untuk mencapai suatu keberhasilan dengan terwujudnya tujuan dari sebuah layanan tersebut. Voluntary counseling and testing ada pun juga untuk mencapai keberhasilan dengan terwujudnya tujuan. Keberhasilan layanan voluntary counseling and testing ditentukan oleh konselor dan klien. Konselor harus profesional dan berkompeten, minimal menguasi keterampilan konseling dan komunikasi, agar layanan voluntary counseling and testing dikatakan berhasil. Klien juga berpengaruh dalam keberhasilan layanan voluntary counseling and testing, untuk mencapai 
keberhasilan klien diperngaruhi oleh kepribadian klien, harapan klien, pengalaman dan pendidikan klien. Hal tersebut meliputi sikap, emosi, intelektual, motivasi, usaha mencari informasi untuk memecahkan masalahya merupakan faktor yang mempengaruhi keberhasilan konseling. Voluntary counseling and testing dikatakan berhasil jika ada perubahan positif pada klien setelah melakukan konseling baik perubahan pada diri sendiri, perilaku, pemahaman, maupun kondisi psikologisnya. Contoh nyatanya seperti adanya perubahan pemahaman tentang pengetahuan VCT serta HIV/AIDS; adanya perubahan pola hidup yang baik, seperti patuh minum obat; adanya perubahan psikologis yang lebih baik, tenang, tidak khawatir; dan klien ikut serta dalam pencegahan HIV/AIDS.

\section{Tahapan Voluntary Counseling and Testing}

Voluntary counseling and testing pada dasarnya merupakan gabungan dari konseling dan tes. Voluntary counseling and testing memiliki 3 tahapan dalam pelaksanaannya, yaitu tahap konseling pra testing, tahap tes HIV, tahap konseling pasca testing.

Konseling Pra Testing. Konseling yang dilakukan sebelum seseorang melakukan tes HIV yang bertujuan untuk membantu klien dalam membuat keputusan yang baik tentang apakah akan menjalani tes HIV atau tidak, dengan sebelumnya klien diberikan informasi yang baik, benar, jelas dan tepat tentang tes HIV dan HIV/AIDS. Langkah-langkah dalam konseling pra testing antara lain adalah

Pertama, Menerima Klien. Menerima klien dilakukan konselor dengan menyambut kedatangan klien, membukakan pintu jika pintu dalam keadaan tertutup, berjabat tangan, menyapa dengan menyebutkan nama jika sudah kenal, jika belum menanyakan nama. Menerima klien dengan hal tersebut agar klien merasa diterima dan diperhatian oleh konselor, sehingga mempermdah proses konseling selanjutnya.

Kedua, Membangun Rapport atau Menjalin Hubungan. Menjalin hubungan bertujuan agar konselor dan klien saling mengenal dan menjalin kedekatan emosional untuk pemecahan masalah dengan menciptakan 
suasana yang santai, nyaman, aman, agar klien merasa tidak takut, percaya dan bebas mengungkapkan perasaan dan pernyataan yang ingin disampaikan sehingga klien percaya dan terbuka kepada konselor. Untuk mewujudkan hal itu dalam menjalin hubungan dilakukan dengan cara konselor memperkenalkan diri; konselor memberikan pertanyaan basa-basi agar situasi mencair seperti menanyakan kabar, kesibukkannya; konselor menanyakan identitas klien; serta konselor menjelaskan peraturan dalam proses konseling yang akan dilakukan, seperti waktu, tujuan, maksud dan kerahasiaan agar klien mengetahui aturan, maksud dan tujuan dari proses konseling.

Ketiga, Eksplorasi. Eksplorasi disebut juga dengan penggalian masalah yang bertujuan untuk mencari tahu permasalahan dan perasaan yang dialami oleh klien. Pertanyaan konselor yang diberikan saat eksplorasi antara lain adalah alasan klien datang kesini, perasaan klien, situasi klien, menggali informasi berkaitan dengan faktor perilaku berisiko HIV, seperti perilaku seksual, tato/tindik, jarum suntik, transfusi darah.

Keempat, Identifikasi. Identifikasi dilakukan konselor untuk membantu klien menentukan permasalahan yang dialami dan mengetahui penyebab permasalahan yang dialaminya. Dalam identifikasi ini konselor membiarkan klien untuk menceritakan permasalahan dan perasaan yang dialaminya. Konselor bertugas mendengarkan dan mengarahkan klien.

Kelima, Memberikan Informasi. Informasi sangat diperlukan dalam voluntary counseling and testing terutama dalam konseling pra testing, karena masih kurangnya informasi tentang voluntary counseling and testing dan HIV/ AIDS. Konselor memberikan informasi dengan baik, jelas, tepat antara lain informasi tentang VCT dan prosedurnya, tentang HIV/AIDS serta penularan HIV/AIDS. Dengan informasi yang didapat dalam tahap ini berguna untuk menentukan keputusan apakah mau menjalani tes HIV atau tidak.

Keenam, Membuat Perencanaan. Setelah informasi didapatkan, selanjutnya yaitu klien dibantu oleh konselor untuk membuat perencanaan dengan cara konselor memberikan alternatif-alternatif perencanaan, serta 
berdiskusi bersama mengetahui kelebihan dan kekeurangan dari alternatif perencanaan.

Ketujuh, Membuat Keputusan. Setelah informasi dan berdiskusi perencaanaan, tibalah saatnya eksekusi yaitu menentukan keputusan apakah mau tes HIV atau tidak. Jika tidak mau, maka konselor diberi kesempatan untuk menyakinkan dan memberikan penguatan kembali, lalu ditanyakan kembali. Jika jawaban tetap tidak, maka konselor tidak boleh memaksa dan proses konseling diakhiri. Jika jawaban mau dites HIV, maka masuk ke tahap berikutnya.

Tes HIV. Proses pengambilan darah sebanyak 2cc untuk dites guna mengetahui status klien apakah positif HIV atau negatif HIV. Namun sebelum tes HIV dilakukan, klien diwajibkan untuk mengisi dan menandatangani surat pernyataan dan persetujuan melakukan tes HIV yang sering disebut informed consent.

Konseling Pasca Testing. Konseling yang dilakukan setelah klien melakukan tes HIV yang bertujuan untuk membacakan hasil tes, membantu klien memahami dan menyesuaikan diri dengan hasil tes, baik itu positif maupun negatif serta memberikan informasi dan penguatan kepada klien. Langkah-langkah dalam konseling pasca testing adalah

Pertama, Menerima Klien. Konselor mempersilakan klien kembali masuk ke ruangan voluntary counseling and testing dengan ramah, baik dan sopan sesuai dengan kode etik konselor.

Kedua, Mengembangkan Hubungan. Konselor mengembangan hubungan dengan klien untuk mengetahui kesiapan mengetahui hasil tes. Yang bisa dilakukan dalam langkah ini adalah konselor menanyakan kesiapan klien. Jika sudah siap, maka lanjut ke langkah berikutnya. Namun jika belum siap, konselor bertugas memotivasi klien hingga siap.

Ketiga, Perencanaan Kegiatan. Konselor membantu klien membuat perencanaan tentang hasil yang akan didapatkan dengan cara melakukan pengandaian jika hasil positif dan negatif. Konselor menanyakan kepada 
klien, jika hasil positif apa yang akan dilakukan dan jika hasil negatif apa yang dilakukan. Cara ini dilakukan untuk membuat klien mengetahui apa yang akan dilakukan dan membuat klien bertanggung jawab kepada dirinya sendiri.

Keempat, Membacakan Hasil Tes. Pada langkah ini, konselor waktunya untuk membacakan hasil tes dan klien mengetahui status kesehatannya. Konselor membacakan hasil tes dengan nada suara yang datar, tidak menunjukkan muka tertentu, tidak tergesa-gesa, dan tidak memberikan komentar. Setelah membacakan hasil tes, konselor diam sejenak untuk menunggu reaksi klien dan untuk memberi waktu klien menerima hasil tes dirinya. Selanjutnya konselor menjelaskan hasil tes yang diterima klien.

Kelima, Integritas Hasil Tes. Dalam langkah integrasi hasil tes ini ada dua, yaitu integrasi kognitif dan integrasi emosional. Integrasi kognitif yaitu mengetahui pemahaman klien tentang HIV sesuai hasil yang diterima. Integrasi kognitif dilakukan oleh konselor dengan menanyakan pengetahuan tentang HIV mengenai hasilnya, setelah itu konselor menambahan jika ada yang kurang dan memperbaiki jika ada yang kurang tepat. Integrasi emosional yaitu mengetahui pengaruh hasil tes yang diterima dengan emosional yang terjadi pada klien. Dan memberikan penguatan kepada klien sesuai dengan hasilnya.

Keenam, Memberikan Informasi. Informasi yang diberikan pada tahap ini disesuaikan dengan hasil tes yang didapatkan klien. Jika hasil negatif, konselor memberikan informasi tentang masa jendela (window period), pola hidup yang baik, dan menyarankan untuk tiga bulan setelah hari tes kembali lagi untuk tes ulang. Jika hasil positif, konselor memberikan informasi apa yang harus dilakukan oleh klien, pola hidup yang baik, menghindari hal-hal yang dapat menularkan HIV/AIDS.

Ketujuh, Memberikan Harapan, Advokasi, Motivasi dan Pemberdayaan. Dalam langkah ini, konselor memberikan harapan, advokasi dan pemberdayaan dengan memberikan pernyataan secara konsisten 
dan realisitis tentang adanya harapan disertai dengan bukti-bukti yang mendukung, memfokuskan pada masalah kualitas hidup dan mendorong klien agar berpartisipasi aktif untuk meningkatkan status kesehatannya.

Kedelapan, Mengidentifikasi Sumber Rujukan yang Memadai. Pada langkah ini konselor membantu klien dalam mengindentifikasi kebutuhan dukungan yang diperlukan oleh klien. Rujukan tersebut meliputi kelompok dukungan sebaya, rumah sakit, puskesmas, terapi individual, intervensi krisis, layanan media, informasi terapi alternatif, rehabilitasi pengguna narkoba, layanan hukum, sosial, psikologis, dan spiritual, serta programprogram lainnya.

Kesembilan, Konselor Melakukan Layanan Lanjutan. Layanan lanjutan terdiri dari konseling lanjutan dan pelayanan penanganan manajemen kasus. Langkah konseling lanjutan ini bisa dilakuan diwaktu lain. Dalam langkah ini konselor melakukan konseling lanjutan bisa dengan pasangan jika mempunyai pasangan, bisa dengan orangtua dan bisa dengan anak. Namun konseling lanjutan harus sesuai dengan persetujuan dari klien. Pelayanan penanganan manajemen kasus bertujuan membantu klien untuk mendapatkan pelayanan berkelanjutan yang dibutuhkan. Tahapan dalam manajemen kasus adalah identifikasi, penilaian kebutuhan pengembangan rencana tindak individu, rujukan sesuai kebutuhan dan tepat dan koordinasi pelayanan tindak lanjut.

\section{Pendukung dan Penghambat Voluntary Counseling and Testing}

Pendukung layanan voluntary counseling and testing dapat berjalan dengan baik yaitu karena adanya kebijakan yang tidak hanya untuk orang berisiko HIV/AIDS namun juga TB, karena TB juga bisa terkena HIV/ AIDS; ruangan yang nyaman, aman; tim VCT yang kompak; klien yang terbuka dan mempunyai kesadaran ingin sembuh; lingkungan yang mau menerima klien sesuai dengan statusnya; dan adanya kelompok dukungan sebaya (KDS). 
Sedang penghambat layanan voluntary counseling and testing adalah kebijakan tentang alokasi pencegahan yang lebih rendah daripada pengobatan; tim VCT yang bertugas merangkap; klien yang tertutup, tidak jujur dan tidak memiliki keinginan untuk sembuh; dan lingkungan yang tidak mau menerima klien sesuai dengan statusnya.

\section{Kesimpulan}

Dengan berjalannya waktu perkembangan HIV/AIDS semakin meningkat untuk membantu perubahan perilaku sehingga risiko tertular HIV menurun, maka pemerintah membuka layanan voluntary counseling and testing. Voluntary counseling and testing terdiri dari tiga tahap, yaitu

Pertama, Konseling Pra Testing. Konseling Pra Testing, yaitu konseling yang dilakukan sebelum seseorang melakukan tes HIV yang bertujuan untuk membantu klien dalam membuat keputusan yang baik tentang apakah akan menjalani tes HIV atau tidak, dengan sebelumnya memberikan informasi tentang tes HIV dan HIV/AIDS. Dalam tahap pertama ini dimulai dengan menerima klien, membangun rapport, eksplorasi, pemahaman, perencanaan tindakan dan membuat keputusan.

Kedua, Tes HIV. Tes HIV, yaitu proses pengambilan darah untuk mengetahui apakah positif HIV atau negatif HIV, sebelum klien tes HIV mengisi surat pernyataan dan persetujuan (informed consent).

Ketiga, Konseling pasca testing. Konseling pasca testing, yaitu konseling yang dilakukan setelah klien melakukan tes HIV yang bertujuan untuk membacakan hasil tes, membantu klien memahami dan menyesuaikan diri dengan hasil tes, baik itu hasilnya positif atau negatif serta memberikan informasi dan penguatan kepada klien. Dalam tahap ini sebelum dibacakan hasil, klien dibantu untuk membuat rencana tentang hasil yang akan diterima. Proses pelaksanaan tahap konseling pasca testing tergantung dengan hasil tes. 


\section{Referensi}

Arikunto, Suharsimi. 2006. Prosedur Penelitian Suatu Penelitian Praktik. Jakarta: Rineka Cipta

A, Hallen. 2005. Bimbingan \& Konseling. Jakarta: Ciputat Pres

Djoerban, Zubairi. 1999. Membidik Aids; Ikhtiar Memahami HIV dan ODHA. Yogyakarta: Yayasan Galang

Departemen Kesehatan RI. 2006. Pedoman pelayanan konseling dan tes sukarela HIV (Voluntary Counseling and Testing. Direktorat Jendral Pengendalian Penyakit dan Penyehatan Lingkungan Departemen Kesehatan. Jakarta: Departemen Kesehatan Republik Indonesia

Eddy Wibowo, Mungin. 2003. Teknik Bimbingan dan Konseling Jilid 1. Jakarta: Tugu Publisher

Green, Chris W. 2013. Seri Buku Kecil HIV Kehamilan \& Kesehatan Perempuan. Yogyakarta: Yayasan Spiritia . 2013. Seri Buku Kecil HIV \& TB. Yogyakarta: Yayasan Spiritia . 2013. Seri Buku Kecil Terapi Penunjang. Yogyakarta: Yayasan Spiritia

Iskandar. 2009. Metodologi penelitian pendidikan dan sosial (kuantitatif dan kualitatif). Jakarta: GP Press

Kartono, Kartini. 1996. Pengantar Metodologi Riset Sosial. Bandung: Mandar Maju

Kementerian Kesehatan. 2011. Pedoman Layanan Konseling dan Tes HIV. Jakarta

Latipun. 2003. Psikologi Konseling. Malang: UPT Penerbit Universitas Muhammadiyah Malang

Lumongga Lubis, Namora. 2011. Memahami Dasar-Dasar Konseling Dalam Teori dan Praktek. Jakarta: Kencana Media Prenada Group

Narbuko, Cholid \& Abu Achmadi. 2003. Metode Penelitian. Jakarta: Bumi Aksara

Mashudi, Farid. 2013. Psikologi Konseling. Jogjakarta: IRCiSoD

Moleong, Lexy J. 2012. Metodologi Penelitian Kualitatif Edisi Revisi. Bandung: Rosdakarya

Murni, Suzana, dkk. 2013. Seri Buku Kecil Pasien Berdaya. Yogyakarta: Yayasan Spiritia 
KPA Klaten. 2015. Mengenal Dan Menanggulangi HIV \& AIDS. Klaten: KPA Klaten

Prayitno dan Amti, Erman. 2013. Dasar-Dasar Bimbingan Dan Konseling. Jakarta: Rineka Cipta

Surya, Moh. 1988. Dasar-dasar Konseling Pendidikan (Konsep dan Teori). Yogyakarta: Kota Kembang

Sutopo, HB. 2002. Metodologi Penelitian Kualitatif. Surakarta: UNS Press

Winkel.W.S. 1991. Bimbingan dan Konseling di Institusi Pendidikan. Jakarta: PT Gramedia Widiasarana Indonesia

Willis, Sofyan. S. 2004. Konseling Individual. Bandung: Alfabeta

Yusuf, Syamsu dan Nurihsan, A. Juntika. 2006. Landasan Bimbingan \& Konseling. Bandung: Remaja Rosdakarya

\section{Sumber Internet}

Desy Arisandy Haya, Pelaksanaan Program Voluntary Counseling and Testing Mobile Dalam Rangka Penanggulangan HIV/AIDS Oleh Komisi Penanggulangan AIDS Kota Bontang, ejournal.an.fisipunmul.ac.id (diakses 10 Oktober 2015)

Suherman, Pengantar Konseling VCT (Dipresentasikan Pada Kongres Nasional Bersama 2007 Diselenggarakan Oleh Fakultas Kedokteran UNPAD RS. Dr. Hasan Sadikin Bandung, Pada tanggal 2 September 2007), http://pustaka.unpad.ac.id/archives/10886 (diakses 9 Januari 2016)

http://spiritia.or.id/Stats/StatCurr.php?lang=id\&gg=1, (diakses 8 Desember 2015)

http:/ / ch2ymanizz.blogspot.co.id/2011/12/psikologi-pasien-hiv-aidsdan-kanker.html (diakses 10 Desember 2015)

http://m/detik.com/health/read/201106/06/171359/1654272/763/3bersaudara-kompak-bunuh-diri-karena-positif-hiv (diakses 12 Januari 2016)

http:/ / fisip.unsoed.ac.id/en/content/penanggulangan-hivaids-dipurwokerto-peran-vct-dalam-penanggulangan-hivaids-di-klinikvct-r (diakses 12 Januari 2016) 